\title{
Comparable response of ccn I with ccn2 genes upon arthritis: An in vitro evaluation with a human chondrocytic cell line stimulated by a set of cytokines \\ Norifumi H Moritani ${ }^{1,2}$, Satoshi Kubota ${ }^{1}$, Toshio Sugahara ${ }^{2}$ and Masaharu Takigawa*1
}

Address: ${ }^{1}$ Department of Biochemistry and Molecular Dentistry, Okayama University Graduate School of Medicine and Dentistry, Okayama 7008525, Japan and ${ }^{2}$ Department of Oral and Maxillofacial Reconstructive Surgery, Okayama University Graduate School of Medicine and Dentistry, Okayama, Japan

Email: Norifumi H Moritani - hachi70@fd5.so-net.ne.jp; Satoshi Kubota - kubota1@md.okayama-u.ac.jp;

Toshio Sugahara - tsugahar@md.okayama-u.ac.jp; Masaharu Takigawa* - takigawa@md.okayama-u.ac.jp

* Corresponding author

Published: 15 April 2005

Cell Communication and Signaling 2005, 3:6 doi:10.1186/1478-8IIX-3-6

This article is available from: http://www.biosignaling.com/content/3/1/6

(c) 2005 Moritani et al; licensee BioMed Central Ltd.

This is an Open Access article distributed under the terms of the Creative Commons Attribution License (http://creativecommons.org/licenses/by/2.0), which permits unrestricted use, distribution, and reproduction in any medium, provided the original work is properly cited.
Received: 29 March 2005

Accepted: 15 April 2005

\begin{abstract}
Background: The chondrosarcoma-derived HCS-2/8 has been known to be an excellent model of human articular chondrocytes. By mimicking the arthritic conditions through the treatment of HCS-2/8 cells with cytokines, we estimated the gene expression response of $\mathrm{ccn} I$ and $\mathrm{ccn} 2$ during the course of joint inflammation in vitro.

Results: In order to mimic the initiation of inflammation, HCS-2/8 cells were treated with tumor necrosis factor (TNF)- $\alpha$. To induce pro-inflammatory or reparative responses, TGF- $\beta$ was employed. Effects of an anti-inflammatory glucocorticoid were also evaluated. After stimulation, expression levels of $c \mathrm{cn} /$ and $\mathrm{ccn} 2$ were quantitatively analyzed. Surprisingly, not only $\mathrm{ccn} 2$, but also ccn I expression was repressed upon TNF- $\alpha$ stimulation, whereas both mRNAs were uniformly induced by transforming growth factor (TGF)- $\beta$ and a glucocorticoid.
\end{abstract}

Conclusion: These results describing the same response during the course of inflammation suggest similar and co-operative roles of these 2 ccn family members in the course of arthritis.

\section{Background}

Osteoarthritis (OA) and rheumatoid arthritis (RA) are most common orthopaedic complexities among aged individuals [1]. Although they may be etiologically distinct each other, both are characterized by progressive destruction of articular cartilage, which is mainly caused by inflammatory stresses [1]. The most major problem in the therapeutics of these joint diseases is the difficulty in regenerating damaged articular cartilage. It is widely recognized that even a defect of $2 \mathrm{~mm}$ in diameter in normal articular cartilage may not be repaired naturally $[2,3]$. Therefore, cartilage regeneration is one of the most preferred subjects for the investigators in medical research field.

In our previous report, we for the first time clarified that CCN2/connective tissue growth factor (CTGF) was capable of regenerating full-thickness defect in articular cartilage and promoted the repair of damaged cartilage in an OA model in vivo [2]. Also, expression of $c c n 2$ in OA cases 
was reported [3]. As such, it is now quite clear that CCN2 is involved in inflammatory response and repair process of articular cartilage during arthritis. Therefore, it is of critical importance to investigate the regulation of $c \mathrm{cn} 2$ expression along with the course of joint inflammation.

The CCN family is a novel group of proteins that act as multiple mediators among a variety of extracellular signaling molecules. This family of secreted proteins consists of 6 members: Cyr61 (CCN1), CTGF (CCN2), Nov (CCN3), Elm-1/WISP-1 (CCN4), rCop-1/WISP-2/CTGF-L (CCN5), and WISP-3 (CCN6) [4-9]. These structurally conserved proteins share 4 modules with sequence similarities to insulin-like growth factor-binding proteins, von Willebrand factor type $\mathrm{C}$ module, thrombospondin type 1 repeat, and growth factor cysteine knots, respectively [49]. CCN2/CTGF is a classical member of CCN family and shares significantly functional similarities with another member, CCN1/Cyr61. Both proteins share $-45 \%$ amino acid sequence identity [10], bind heparin, are associated with the ECM [11], and exhibit remarkable functional versatility $[12,13]$. CCN1 and CCN2 can stimulate chemotaxis and promote proliferation of endothelial cells and fibroblasts in culture, induce neovascularization in vivo, and promote chondrogenic differentiation, the last-mentioned action being consistent with their expression in prechondrogenic mesenchyme during embryogenesis [57,13-15]. Considering such biological involvement of CCN1 in mesenchymal tissue formation, active roles of $\mathrm{CCN} 1$ in cartilage regeneration and repair may not be disregarded as well.

Therefore, in our present study, we assessed the gene regulation profile of CCN1 as well as CCN2 in a human chondrocytic cell line, HCS-2/8, upon the stimulation mimicking the course of chronic inflammation. This particular cell line was selected, since HCS-2/8 was established from a chondrosarcoma and has best retained a variety of mature chondrocytic phenotypes [16-18]. Using this in vitro model, we found CCN1 may also be involved in the inflammatory response in joints and may be useful in cartilage regenerative therapeutics, as described in CCN2.

\section{Results \\ Strict and discriminating quantification of ccn I and ccn2 mRNAs by real-time-RT-PCR}

Since $c c n 1$ and $c c n 2$ are members of the same gene family, it is critically important to examine the specificity of each quantification system in order to avoid possible cross-recognition [4]. First, RT-PCR products of the initial amplification under our protocol were separated by $2 \%$ agarose gel electrophoresis. All of the amplified LightCycler-PCR products showed single bands of the expected lengths (i.e., 219 bp for CCN1, 153 bp for CCN2, and 101 bp for $\beta$-actin; Fig. 1B). Second, we further verified the identity of each PCR product by direct nucleotide sequencing. As a result, sequence analysis of the PCR products showed 100 $\%$ homology to the published sequences. After these initial examinations, specificity of all of the products was confirmed each time by melting curve analysis via LightCycler Software 3.39 (Roche). Melting curves were analyzed for all PCR runs. Continuous fluorescence monitoring while slowly elevating the temperature resulted in a sudden decrease in SYBR green I (Roche) fluorescence intensity, when denaturation of the PCR product occurred. Thus, the melting curve analysis revealed a specific pattern for each target. Figure $1 \mathrm{C}$ shows an example of a melting curve analysis, indicating no nonspecific PCR product. As such, accurate and distinctive quantification of $\operatorname{ccn} 1$ and $c c n 2$ was deemed warranted.

\section{Repressive response of both ccn I and ccn2 genes upon inflammatory provocation by TNF- $\alpha$}

TNF- $\alpha$ is one of the best-known inflammatory cytokines and is involved in a number of inflammatory diseases including arthritis [1]. Therefore, we evaluated the effect of TNF- $\alpha$ on the expression of the $c c n 1$ and $c c n 2$ genes in the chondrocytic HCS-2/8 cells. HCS-2/8 cells were treated with $10 \mathrm{nM}$ TNF- $\alpha$ for $12-24$ hours. By this stimulation, $c c n 2 \mathrm{mRNA}$ levels were repressed 0.6 (0.64) to 0.4 (0.41) fold, and ccn1 mRNA levels, 0.9 (0.89) to 0.7 (0.66) fold, by $24 \mathrm{~h}$ (Fig. 2A). The result that both genes were uniformly downregulated upon TNF- $\alpha$ stimulation strongly suggests similar or complementary functions of these gene products in the middle of inflammatory process.

\section{Induction of ccn I and ccn2 by pro-inflammatory and regenerative signal in chondrocytic $\mathrm{HCS}-2 / 8$ cells}

Tissue repair and regeneration are the last step of inflammation, in which damaged tissue is initially filled with fibroblasts surrounded by a vast amount of extracellular matrices (ECM). However, in general, inflammatory stimulation and ECM formation occur in parallel along the course of chronic inflammation. Through such process, TGF- $\beta$ and CCN2 is known to critically regulate ECM deposition from a variety of mesenchymal cells. Molecular regulation of $c c n 2$ by TGF- $\beta$ has been relatively investigated $[19,20]$. Nevertheless, little is known concerning the interplay between $c c n 1$ and TGF- $\beta$ in cartilage. As such, we evaluated the response of $c c n 1$ gene in chondrocytic HCS$2 / 8$ cells to TGF- $\beta$, in comparison with $c c n 2$. Treatment with $10 \mathrm{ng} / \mathrm{ml}$ TGF- $\beta$ induced $c c n 2 \mathrm{mRNA}$ up to 1.5 to 1.9 fold; and $c c n 1$ mRNA, by 1.5 fold up to 24 h (Fig. 2B). Additionally, we found that these mRNAs were better induced by $50 \mathrm{ng} / \mathrm{ml}$ TGF- $\beta$ than by $10 \mathrm{ng} / \mathrm{ml}$ (data not shown). These findings suggest coordinative functions of $c c n 1$ and $c c n 2$ in repair and chronic inflammation of articular cartilage. 
A
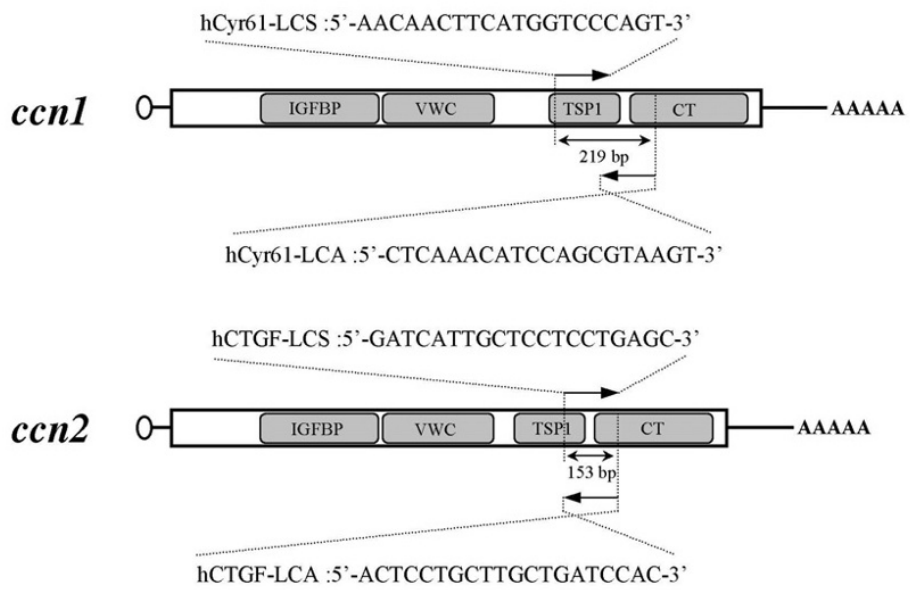

$\mathrm{B}$

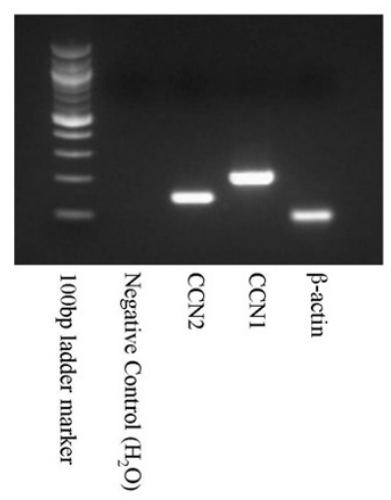

$\mathrm{C}$
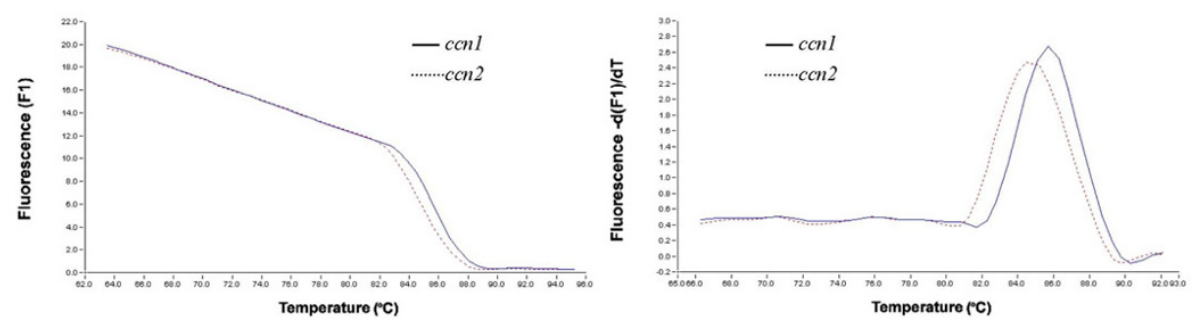

\section{Figure I}

Distinctive quantification of ccn I and ccn 2 mRNA by real-time RT-PCR. A. Primers used for real-time PCR and the structures of human $c \mathrm{cn} /$ and $c \mathrm{cn} 2 \mathrm{mRNAs}$. Schematic representations are illustrated in reference to the modular structure of human CCNI and CCN2 (stippled boxes). The small open circle and AAAAA at the left and right ends denote the 5'-cap structure and poly-A tail, respectively. Names, locations for recognition, nucleotide sequence of the primers, and the expected sizes of the PCR products are given. Abbreviations: IGFBP, insulin-like growth factor binding module; VWC, von Willebrand factor type C module; TSPI, thrombospondin type I repeat; CT, C-terminal module. B. The CCNI (219 bp), CCN2 (I53 bp), and $\beta$-actin (IOI bP) PCR products amplified by LightCycler were analyzed by agarose electrophoresis. $\mathbf{C}$. Melting curve analysis of the RT- PCR products of $c \mathrm{cn} /$ and $c \mathrm{cn} 2$. Melting curves were acquired after 45 cycles of amplification. Melting curve pattern is displayed on the left panel, where fluorescent intensity (FI) from SYBR green is plotted against temperature. Melting peak pattern can be found on the right panel, in which the decrement of $\mathrm{FI}$ is plotted against temperature. 
A

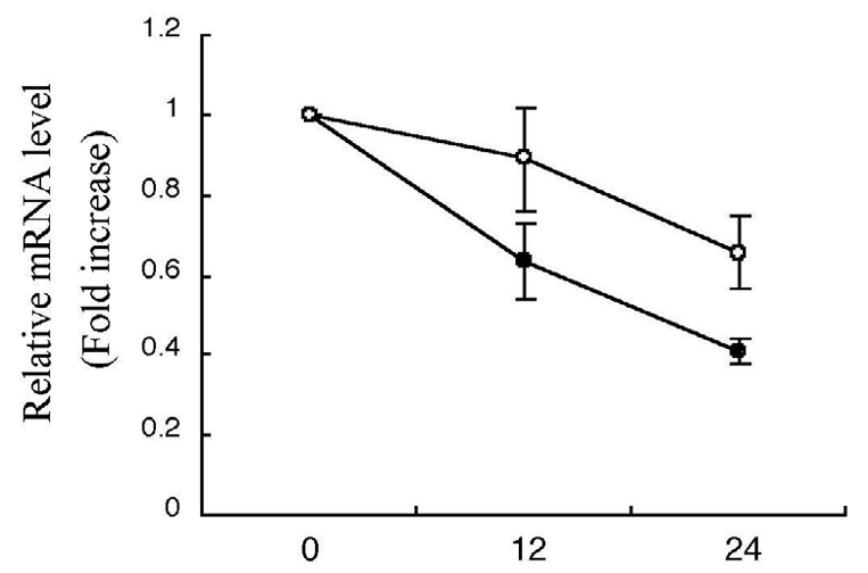

Time after TNF- $\alpha(\mathrm{h})$

B

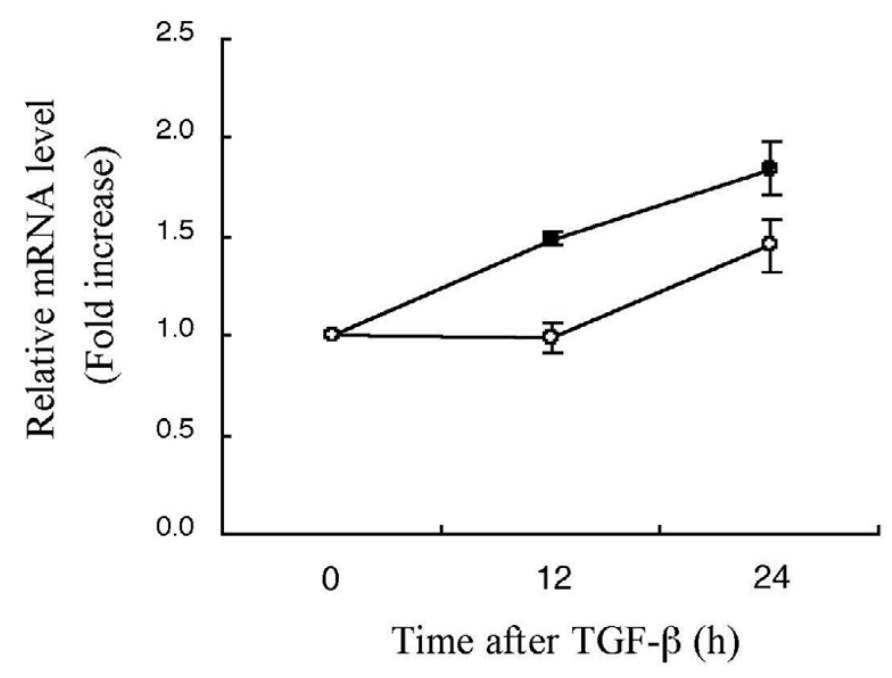

\section{Figure 2}

Coordinative repression and induction of $c \mathrm{cn} I$ and $\mathrm{ccn} 2$ transcripts in response to inflammatory TNF- $\alpha$ (A) and pro-inflammatory TGF- $\beta$ (B) in chondrocytic HCS-2/8 cells. Results of mRNA quantification by real-time RT-PCR analysis are displayed. Plotted values represent relative mRNA copy numbers versus those at time 0 . Each copy number was computed by standardizing the raw data against those of $\beta$-actin. Open circles, $c \mathrm{cn} /$; solid circles, $c \mathrm{cn} 2$. Mean values and standard deviations (SDs) of at least 2 experiments are shown. 


\section{Anti-inflammatory treatment and expression of ccn I and con2 genes}

Glucocorticoids are known to possess strong anti-inflammatory effects and also to be involved in the control of cartilage metabolism [21]. Particularly, the effectiveness of glucocorticoids on RA symptom is so prominent that it is frequently applied clinically, despite its adverse systemic effects. It is already known that $c c n 2$ gene expression is induced by glucocorticoids in chondrocytic cells as well as in fibroblasts $[22,23]$. In contrast, molecular interaction between glucocorticoids and $c c n 1$ gene in chondrocytes has not been investigated. Thus, we performed Northern blot analysis, as well as the real-time RT-PCR quantification to estimate the effects of glucocorticoids on ccn 1 and $c c n 2$ gene expression. When HCS-2/8 cells were treated with $50 \mathrm{nM}$ dexamethasone for 2.5 - 5 hours and then examined by real-time PCR, $c c n 2$ mRNA was induced by 1.8 to 2.3 fold, and $c c n 1$ mRNA was similarly induced by 1.5 to 1.9 fold up to $5 \mathrm{~h}$ (Fig. 3A). The results obtained by Northern blot analysis were quite similar to the PCR ones (Fig 3B).

As a control experiment, we carried out similar analysis with $17 \beta$-estradiol, which is another steroid hormone and is also one of the regulators to maintain the homeostasis of connective tissue. However, treatment of HCS-2/8 cells with $10 \mathrm{nM}$ estrogen for $1-24$ hours resulted in no significant change in $c c n 1$ and $c c n 2$ mRNA expression levels. In fact, no effects were observed even up to the concentration of $100 \mathrm{nM}$ (data not shown).

\section{Discussion}

In this study, we comparatively analyzed the expression profiles of $c c n 1$ and $c c n 2$, while simulating the course of arthritis; i.e., inflammation, tissue regeneration and antiinflammatory treatment, utilizing a human chondrocytic HCS-2/8. In advance to the evaluation, we established a real-time PCR quantification method by using a LightCycler system. In view of the data provided for sensitivity, linearity, and reproducibility, this assay system accurately allowed the discriminating quantification of these mRNAs from the same gene family. The total reliability of this system was evident, as represented by the facts that every specific primer set produced distinct and specific PCR products (Fig. 1) and quantitative results were comparable to those of Northern blot analysis (Fig. 3).

The involvement of CCN2 in arthritic diseases has been indicated. In fact, expression of $c c n 2$ gene in clinical cases was reported [3]. Also in an experimental OA model, distinct induction of ccn2 gene expression was observed. These findings are regarded as a regenerative response of damaged cartilage, since exogenously applied CCN2 was proven to be effective in cartilage regeneration. In rat models, CCN2 captured in collagen hydrogel to allow gradual release of this factor efficiently promoted the regeneration of full-thickness cartilage defect and experimentally induced OA cartilage [2]. Therefore, expression profile of $c c n 2$ in chondrocytes along the time course of inflammation is thought to represent the proper gene regulation to provide a regenerative molecule during arthritis, and thus itself is worth investigated. More interestingly, ccn1 gene expression exactly followed the fluctuation pattern of $c c n 2$ gene expression upon any kind of stimulation tested. These results clearly indicate that not only CCN2, but also CCN1 may be provided as a regenerative molecule in arthritis. This hypothesis is supported by a number of their functional similarities. Indeed, these factors are associated with the ECM, stimulate chemotaxis and promote proliferation of endothelial cells and fibroblasts, and promote neovascularization and chondrogenic differentiation [7-15,24]. Considering such similarities and the concomitant fluctuation of gene expression upon inflammation together, CCN1 is expected to be one of the useful molecular tools to promote cartilage regeneration. In order to examine this hypothesis, it is necessary to evaluate the regenerative potential of $\mathrm{CCN} 1$ protein in damaged articular cartilage, as was examined with $\mathrm{CCN} 2$. In vivo evaluation of the expression of $c c n 1$ upon OA and RA and the effects of CCN1 protein on cartilage regeneration is currently in progress. Since all of the CCN family members are thought to be mediators of multiple signaling molecules, therapeutic utility of another member, such as CCN3/ NOV is also expected and obviously, need to be explored.

\section{Conclusion}

In vitro simulation of arthritis with a human chondrocytic cell line revealed the same response pattern of $c c n 1$ as that of $c c n 2$, which is known as a regenerative mediator in cartilage repair. Together with similar functionalities of CCN1 and CCN2 in mesenchymal tissues, these results suggest possible utility of $\mathrm{CCN} 1$ in regenerative therapy of damaged mesenchymal tissues.

\section{Methods \\ Materials}

TNF- $\alpha$ and TGF- $\beta 1$ were purchased from Promega (Madison, WI, USA). Dexamethasone and estrogen (17 $\beta$-estradiol) were purchased from Sigma (St. Louis, MO,USA).

\section{Cell culture}

HCS-2/8 cells, a chondrocytic cell line derived from a well-differentiated type of human chondrosarcoma [19], were maintained in Dulbecco's modified Eagle's medium (D-MEM) supplemented with $10 \%$ fetal bovine serum (FBS) under an atmosphere of humidified air containing $5 \% \mathrm{CO}_{2}$. In the experiments in which the effect of estrogen was studied, the medium was replaced with phenol red-free DMEM and $2 \mathrm{mM}$ glutamine (Nissui 
A

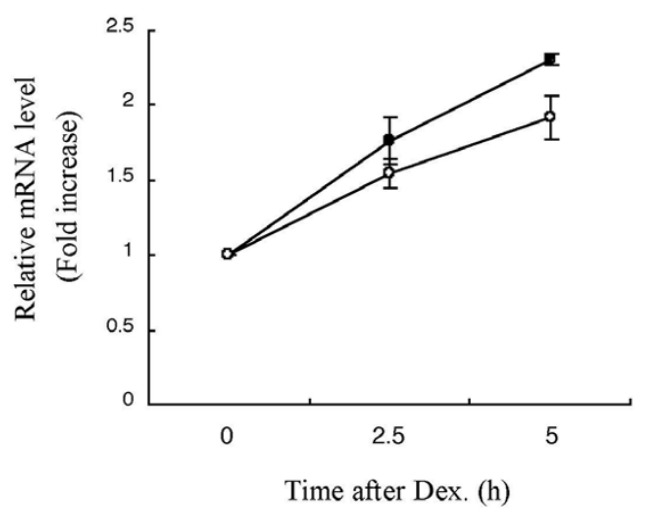

B

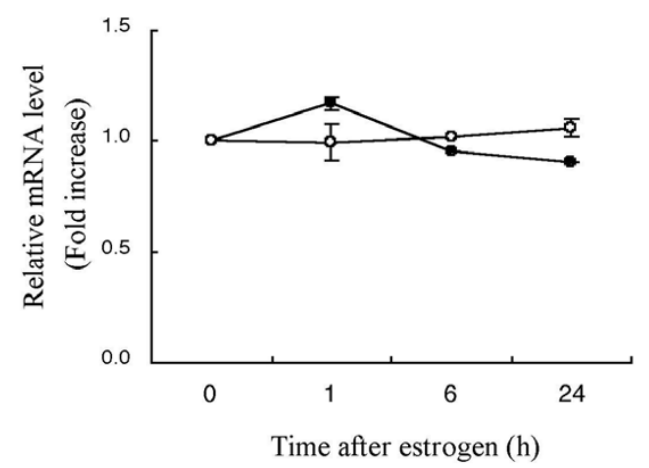

$\mathrm{C}$

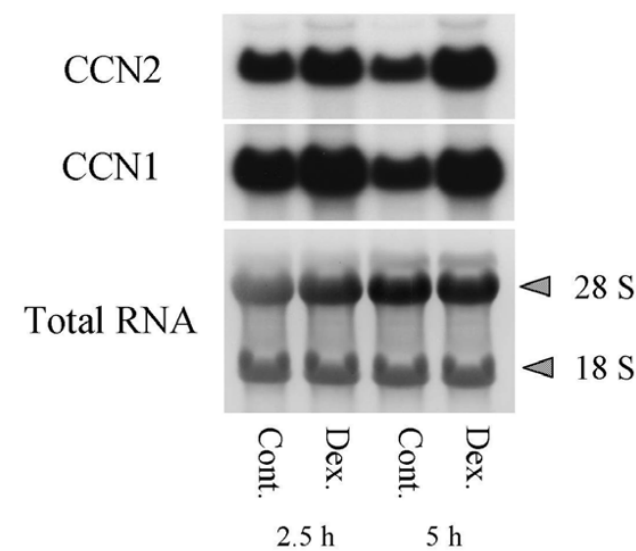

Figure 3

Comparable response of $\mathrm{ccn} I$ and $\mathrm{ccn} 2$ to anti-inflammatory dexamethasone in HCS-2/8 cells. A. Expression levels of $c \mathrm{cn} I$ and $c \mathrm{cn} 2$ transcripts examined by quantitative real-time PCR. Plotted values represent relative mRNA copy numbers, as described in the legend to Figure 2. Open and solid circles denote $c \mathrm{cn} / \mathrm{I}$ and $\mathrm{ccn} 2$, respectively. B. Control experiments with estrogen, showing no significant alteration in gene expression either in $\mathrm{ccn} I$, or $\mathrm{ccn} 2$. These data are mean values of 2 experimental results shown with error bars (SD). C. Northern blot analysis of $\mathrm{ccn} /$ and $c \mathrm{cn} 2$ gene expression in HCS-2/8 cells in response to dexamethasone treatment. The $c \mathrm{cn} /$ and $c \mathrm{cn} 2 \mathrm{mRNAs}$ (upper and middle panels) and total RNAs stained with $0.02 \%$ methylene blue (lower panel) are shown. : 28S, 28S ribosomal RNA; I8S, I8S ribosomal RNA. 
Pharmaceutical Co. Ltd., Tokyo, Japan) containing $2 \%$ charcoal-treated FBS, after the HCS-2/8 cells had become subconfluent. In the experiments with TGF- $\beta 1$, dexamethasone, and estrogen, the cells were harvested after the treatment of subconfluent cells (simulating growing phase upon regeneration) with each factor for the desired time periods. In the TNF- $\alpha$ experiment, the cells were harvested after the treatment of confluent cells (simulating quiescent phase before inflammatory damage) with the factor for the desired time periods.

\section{RNA extraction and reverse transcription (RT)}

Total RNA was extracted from HCS-2/8 cells by the acid guanidinium phenol-chloroform method previously described [25]. Reverse transcription by avian myelosarcoma virus reverse transcriptase was carried out by using a commercially available kit (Takara Shuzo, Tokyo, Japan) and $1.0 \mu \mathrm{g}$ of total RNA. Then, the samples were diluted by 20 -fold with RNase-free $\mathrm{H}_{2} \mathrm{O}$ for subsequent quantification.

\section{Quantitative real-time PCR amplification}

On the basis of the published cDNA sequences of CCN2/ CTGF (GenBank accession no. NM_001901) and CCN1/ Cyr61 (no. AF031385), specific primers were designed for each. Their nucleotide sequences are displayed in Fig. 1. Real-time quantitative PCR was performed with a LightCycler system (Roche Molecular Biochemicals, Mannheim, Germany). For each assay, reaction mixtures containing $2.0 \mu \mathrm{l}$ of a cDNA pool, $1.0 \mu \mathrm{l}$ of LC DNA Master SYBR Green I mixture (Roche), 50 ng of the primers, and $0.8 \mu \mathrm{l}$ of $25 \mathrm{mM} \mathrm{MgCl}_{2}$ were prepared on ice. After the reaction mixtures had been loaded into glass capillary tubes, amplification was performed under the following cycling conditions: initial denaturation at $95^{\circ} \mathrm{C}$ for 10 min, followed by 45 cycles of denaturation at $95^{\circ} \mathrm{C}$ for 15 sec, annealing at $55^{\circ} \mathrm{C}$ for $10 \mathrm{sec}$, and extension at $72^{\circ} \mathrm{C}$ for $10 \mathrm{sec}$. The temperature transition rate was set at $20^{\circ} \mathrm{C} / \mathrm{sec}$. The fluorescence representing double-strand DNA formation was measured in single-acquisition mode at $72^{\circ} \mathrm{C}$ after each cycle. For each sample, the cDNA copy numbers of the target and an internal control ( $\beta$-actin) genes were determined based on calibration curves (see below). The relative amount of the target cDNA was then computed by dividing the copy number by that of the internal control to obtain a normalized value. Separate calibration curves for $c c n 1, c c n 2$, and $\beta$-actin were prepared with serially diluted plasmid DNAs containing the target sequences, which were amplified and evaluated simultaneously in each assay. To distinguish specific signal from non-specific products, melting curve analysis was performed after each amplification cycle. Samples were maintained at $63^{\circ} \mathrm{C}$ for $10 \mathrm{sec}$, and then the temperature was gradually increased to $95^{\circ} \mathrm{C}$ at a rate of $0.1^{\circ} \mathrm{C} / \mathrm{sec}$, while the signals were monitored with a step-acquisition mode, as described previously [26]. The real-time PCR analysis condition was optimised to a level without nonspecific amplification under an acceptable PCR efficiency (a slope ranging from -2.9 to -4.5). To verify the melting curve results, we analyzed representative PCR samples in $2.0 \%$ agarose gels, purified and directly sequenced them from both directions by an automated DNA sequencer (ABI prism 310 Genetic Analyzer; Applied Biosystems, Foster City, CA, USA).

\section{Northern blot analysis}

Ten micrograms of total RNA was electrophoresed in formaldehyde agarose gel and subsequently blotted onto a nylon membrane. For hybridization probes, CCN2/CTGF and CCN1/Cyr61 cDNA fragments were prepared by RTPCR with pairs of specific primers. Primers specific for CCN2/CTGF [27] and CCN1/Cyr61 [28] were described previously. These PCR products were radiolabeled and used for hybridization as described earlier [20].

\section{Competing interests}

The author(s) declare that they have no competing interests.

\section{Authors' contributions}

NHM performed molecular biological studies and prepared most part of data. SK arranged the constitution of the entire work and drafted the manuscript. TS participated in the design of the work. MT participated in coordination and drafting the manuscript and provided general support.

\section{Acknowledgements}

This work was supported in part by grants from the program Grants-in-Aid for Scientific Research (C) (to S.K.) and (S) (to M.T.) and Exploratory Research (to M.T.) from the Ministry of Education, Culture, Sports, Science and Technology of Japan; the Naito Foundation (to M.T.); the Nakatomi Health Science Foundation (to S.K., M.T.); Ryobi-teien Memorial Foundation (to S.K.); the Foundation for Growth Science in Japan (to M.T.); and the Sumitomo Foundation (to M.T.). The authors wish to thank Drs. Tohru Nakanishi, Takashi Nishida, Takanori Eguchi, Seiji Kondo, Hideyuki Doi, and Kyouji Nakao for helpful suggestions and discussions; Mr. Shosai Moritani and Ms. Hiroko Moritani for overall assistance; and Ms. Yuki Nonami for secretarial help..

\section{References}

I. Reines BP: Is rheumatoid arthritis premature osteoarthritis with fetal-like healing? Autoimmun Rev 2004, 3:305-3 I I.

2. Nishida T, Kubota S, Kojima S, Kuboki T, Nakao K, Kushibiki T, Tabata $Y$, Takigawa M: Regeneration of defects in articular cartilage in rat knee joints by CCN2 (connective tissue growth factor). J Bone Miner Res 2004, I 9: | 308- I319.

3. Omoto S, Nishida K, Yamaai Y, Shibahara M, Nishida T, Doi T, Asahara $\mathrm{H}$, Nakanishi T, Inoue H, Takigawa M: Expression and localization of connective tissue growth factor (CTGF/Hcs24/ CCN2) in osteoarthritic cartilage. Osteoarthritis Cartilage 2004, | 2:77|-778.

4. Bork P: The modular architecture of a new family of growth regulators related to connective tissue growth. FEBS Lett 1993, 327:125-130. 
5. Brigstock DR: The connective tissue growth factor/cysteinerich $61 /$ nephroblastoma overexpressed (CCN) family. Endocr $\operatorname{Rev}$ 1999, 20:189-206.

6. Lau LF, Lam SC: The CCN family of angiogenic regulators: the integrin connection. Exp Cell Res 1999, 248:44-57.

7. Takigawa M, Nakanishi T, Kubota S, Nishida T: The role of CTGFI Hcs24/ecogenin in skeletal growth control. J Cell Physiol 2003, 194:256-266.

8. Takigawa M: CTGF/Hcs24 as a multifunctional growth factor for fibroblasts, chondrocytes and vascular endothelial cells. Drug News Perspect 2003, 16:1 I-2I.

9. Perbal $B: C C N$ proteins: multifunctional signalling regulators. Lancet 2004, 363:62-4.

10. Brunner A, Chinn J, Neubauer M, Purchio AF: Identification of a gene family regulated by transforming growth factor-beta. DNA Cell Biol 1991, 10:293-300.

II. Kubota S, Eguchi T, Shimo T, Nishida T, Hattori T, Kondo S, Nakanishi T, Takigawa M: Novel mode of processing and secretion of connective tissue growth factorlecogenin (CTGF/Hcs24) in chondrocytic HCS-2/8 cells. Bone 200I, 29:|55-I6I.

12. O'Brien TP, Yang GP, Sanders L, Lau LF: Expression of cyr6I, a growth factor-inducible immediate-early gene. Mol Cell Biol 1990, 10:3569-77.

13. O'Brien TP, Lau LF: Expression of the growth factor-inducible immediate early gene cyr6 I correlates with chondrogenesis during mouse embryonic development. Cell Growth Differ 1992 3:645-654.

14. Ryseck RP, Macdonald-Bravo H, Mattei MG, Bravo R: Structure, mapping, and expression of fisp- I 2, a growth factor-inducible gene encoding a secreted cysteine-rich protein. Cell Growth Differ 1991, 2:225-33.

15. Wong M, Kireeva ML, Kolesnikova TV, Lau LF: Cyr6I, product of a growth factor-inducible immediate-early gene, regulates chondrogenesis in mouse limb bud mesenchymal cells. Dev Biol 1997, 192:492-508.

16. Takigawa M, Tajima K, Pan HO, Enomoto M, Kinoshita A, Suzuki F, Takano Y, Mori Y: Establishment of a clonal human chondrosarcoma cell line with cartilage phenotypes. Cancer Res 1989, 49:3996-4002.

17. Takigawa M, Pan HO, Kinoshita A, Tajima K, Takano Y: Establishment from a human chondrosarcoma of a new immortal cell line with high tumorigenicity in vivo, which is able to form proteoglycan-rich cartilage-like nodules and to respond to insulin in vitro. Int J Cancer I991, 48:717-725.

18. Moritani NH, Kubota S, Eguchi T, Fukunaga T, Yamashiro T, TakanoYamamoto T, Tahara H, Ohyama K, Sugahara T, Takigawa M: Interaction of AP-I and the ctgf gene: a possible driver of chondrocyte hypertrophy in growth cartilage. J Bone Miner Metab 2003, 21:205-10.

19. Mori T, Kawara S, Shinozaki M, Hayashi N, Kakinuma T, Igarashi A, Takigawa M, Nakanishi T, Takehara K: Role and interaction of connective tissue growth factor with transforming growth factor-beta in persistent fibrosis: A mouse fibrosis model. J Cell Physiol 1999, 181:153-159.

20. Nakanishi T, Kimura $Y$, Tamura T, Ichikawa H, Yamaai $Y$, Sugimoto $T$, Takigawa M: Cloning of a mRNA preferentially expressed in chondrocytes by differential display-PCR from a human chondrocytic cell line that is identical with connective tissue growth factor (CTGF) mRNA. Biochem Biophys Res Commun 1997, 234:206-210.

21. Takano T, Takigawa M, Suzuki F: Stimulation by glucocorticoids of the differentiated phenotype of chondrocytes and the proliferation of rabbit costal chondrocytes in culture. J Biochem (Tokyo) 1985, 97:1093-1100.

22. Dammeier J, Beer HD, Brauchle M, Werner S: Dexamethasone is a novel potent inducer of connective tissue growth factor expression. Implications for glucocorticoid therapy. I Biol Chem 1998, 273:18185-18190.

23. Kubota S, Moritani NH, Kawaki H, Mimura H, Minato M, Takigawa M: Transcriptional induction of connective tissue growth factorl hypertrophic chondrocyte-specific 24 gene by dexamethasone in human chondrocytic cells. Bone 2003, 33:694-702.

24. Nakanishi T, Nishida T, Shimo T, Kobayashi K, Kubo T, Tamatani T, Tezuka K, Takigawa M: Effects of CTGF/Hcs24, a product of a hypertrophic chondrocyte-specific gene, on the proliferation and differentiation of chondrocytes in culture. Endocrinology 2000, I $41: 264-73$.

25. Moritani NH, Kubota S, Nishida T, Kawaki H, Kondo S, Sugahara T, Takigawa M: Suppressive effect of overexpressed connective tissue growth factor on tumor cell growth in a human oral squamous cell carcinoma-derived cell line. Cancer Lett 2003, | 92:205-2|4

26. Woo TH, Patel BK, Cinco M, Smythe LD, Symonds ML, Norris MA, Dohnt MF: Real-time homogeneous assay of rapid cycle polymerase chain reaction product for identification of Leptonema illini. Anal Biochem 1998, 259: I I2-I I7.

27. Moritani NH, Kubota S, Nishida T, Kawaki H, Kondo S, Sugahara T, Takigawa M: Suppressive effect of overexpressed connective tissue growth factor on tumor cell growth in a human oral squamous cell carcinoma-derived cell line. Cancer Lett 2003, | 92:205-2|4.

28. Babic AM, Kireeva ML, Kolesnikova TV, Lau LF: CYR6I, a product of a growth factor-inducible immediate early gene, promotes angiogenesis and tumor growth. Proc Natl Acad Sci USA 1998, 95:6355-6360.
Publish with Biomed Central and every scientist can read your work free of charge

"BioMed Central will be the most significant development for disseminating the results of biomedical research in our lifetime. "

Sir Paul Nurse, Cancer Research UK

Your research papers will be:

- available free of charge to the entire biomedical community

- peer reviewed and published immediately upon acceptance

- cited in PubMed and archived on PubMed Central

- yours - you keep the copyright 